\title{
Prospective randomised evaluation of traditional Chinese medicine combined with chemotherapy: a randomised phase II study of wild toad extract plus gemcitabine in patients with advanced pancreatic adenocarcinomas
}

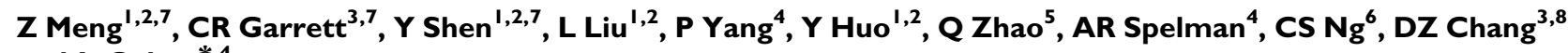 \\ and $L$ Cohen $*, 4$
}

'Department of Integrative Oncology, Fudan University Shanghai Cancer Center, Shanghai, China; ${ }^{2}$ Department of Oncology, Shanghai Medical College, Fudan University, Shanghai, China; ${ }^{3}$ Department of Gastroinestinal Medical Oncology, The University of Texas MD Anderson Cancer Center, 1515 Holcombe Boulevard, Unit 410, Houston, TX 77030-4095, USA; ${ }^{4}$ Integrative Medicine Program, Department of General Oncology, The University of Texas MD Anderson Cancer Center, 1515 Holcombe Boulevard (CPB 3.3263), Unit 410, Houston, TX 77030-4095, USA; ${ }^{5}$ Department of Epidemiology, School of Public Health, Fudan University, Shanghai, China; ${ }^{6}$ Department of Radiology, The University of Texas MD Anderson Cancer Center, 1515 Holcombe Boulevard, Unit 410, Houston, TX 77030-4095, USA

BACKGROUND: An intravenous formulated extract of the venom of the wild toad Bufo bufo gargarizans Cantor or Bufo melanostictus Schneider, huachansu, is currently used in China for the treatment of lung, liver, pancreatic, and colorectal cancers. We performed a randomised, single-blinded, phase II clinical study of huachansu plus gemcitabine versus placebo plus gemcitabine in patients with locally advanced and/or metastatic pancreatic adenocarcinomas.

METHODS: Patients with tissue-proven locally advanced and/or metastatic pancreatic adenocarinoma were randomly assigned to receive either gemcitabine $1000 \mathrm{mg} \mathrm{m}^{-2}$ on days I, 8 , and 15 with huachansu $20 \mathrm{ml} \mathrm{m}^{-2}$ daily for 21 days (arm A) or placebo (arm B); treatment cycles were 28 days in length. Primary end point was 4-month progression-free overall survival (PFS); secondary end points were objective radiographical response rate (ORR), time to progression (TTP), and toxicity.

RESULTS: A total of 80 subjects were enrolled; 76 patients were evaluable (received at least I week therapy). Median overall survival was 160 days for arm $A$ and 156 days for arm B $(P=0.339)$; ORR was 9 and $3 \%$ in arms $A$ and $B$, respectively $(P=0.332)$, median TTP was 98 and II 5 days, respectively $(P=0.825)$; the median 4-month PFS was 99 and 98 days, respectively $(P=0.679)$. CONCLUSION: Huachansu when combined with gemcitabine did not improve the outcome of patients with locally advanced and/or metastatic pancreatic cancer.

British Journal of Cancer (2012) 1 07, 4II-4I6. doi:I0.1038/bjc.20 I2.283 www.bjcancer.com

Published online 10 July 2012

(C) 2012 Cancer Research UK

Keywords: huachansu; gemcitabine; pancreatic cancer; traditional Chinese medicine

Traditional Chinese medicine (TCM) is currently practiced worldwide, and is frequently used to treat cancer, either alone or in combination with Western medicines. Natural products have long been an important source of cancer therapies (Cragg et al, 1993; Cragg et al, 1997; Boik, 2001; Wei et al, 2007). Chansu, the dried secretion from the skin glands of Bufo bufo gargarizans Cantor or B. melanostictus Schneider, has been used clinically for over a

\footnotetext{
*Correspondence: Dr L Cohen; E-mail: Icohen@mdanderson.org

${ }^{7}$ These authors contributed equally to this work.

${ }^{8}$ Current Address: DZC Virginia Oncology Associaties, Newport News, VA 23606, USA.

Presented at the Gastrointestinal Cancers Symposium, 20-22 January 20II, San Francisco, CA, USA, and at the American Society of Clinical Oncology, 4-8 June 201 I, Chicago, IL, USA.

Received 24 January 2012; revised 17 May 20 I2; accepted 30 May 20 I2; published online 10 July 2012
}

millenium as a TCM (Su and $\mathrm{Nu}, 2001)$. Huachansu, an injectable form of chansu, is a sterilised hot water extract of the dried toad skin and is used for the treatment of liver, lung, pancreatic, and colorectal cancers in China. Its two primary biologically active chemical components are indole alkaloids (bufotenine, bufotenidine, cinobufotenine, and serotonin) and steroidal cardiac glycosides (more than 28 have been identified, including bufalin, resibufogenin, cinobufagin, cinobufotalin, marinobufagin, and bufotalin) (Su et al, 2003). Recent studies have demonstrated that bufalin, resibufogenin, and cinobufagin are the three major cardiac glycosides to which the anticancer activity of huachansu can be attributed (Su et al, 2003). Among its other multiple effects are inhibition of vasodilation (vasoconstriction), anti-inflammation, increased vascular resistance, and inhibition of cancer proliferation ( $\mathrm{Su}$ and $\mathrm{Nu}, 2001)$.

In vitro studies demonstrated that huachansu, at a dose of $2 \mathrm{mg} \mathrm{ml}^{-1}$, based on raw material, inhibited human hepatocellular (SMMC-72), gastric (MKN45), and colon cancer (lovo) cell line 
proliferation (Zhang et al, 1999). In addition, huachansu also inhibited proliferation and induced apoptosis in gastric carcinoma MGC-80-3 cells with an $\mathrm{IC}_{50}$ of $0.16 \mu \mathrm{g} \mathrm{ml}^{-1}$ (based on extract weight) (Cuo et al, 2003a). It was also reported that the growth of human hepatocellular cells lines (MGC-80-3 and SMMC-7721) were inhibited by huachansu $\left(0.2 \mathrm{mcg} \mathrm{ml}^{-1}\right)$ and that this was mediated through S-phase arrest and inhibition of bcl-2 expression (Cuo et al, 2003b). Furthermore, huachansu markedly inhibited the biosynthesis of DNA and RNA in $\mathrm{H} 22 \mathrm{AH}$, ascitic hepatoma cells in vitro, and the effect was concentration-dependant (Guan et al, 1993). When human breast cancer cells, BCF-7, and lung cancer cells, A549, were treated with huachansu, the drug significantly inhibited the growth of A549 cells, but not BCF-7 cells, which suggested that the antiproliferative activity of huachansu might be cell type specific (Liu et al, 2002). More recently, Wang et al (2000) reported that the morphology and proliferative activity of NIH 3T3 cells could be inhibited by huachansu in a dose-dependent manner. Huachansu can be immunostimulative as indicated by increased activity of mouse spleen rosette forming cell, macrophage activity, levels of plasma lysozyme, and B-cell function (Sun et al, 1984; Yang and Zhang, 1987). When tested in vitro, we demonstrated an inhibition of human pancreatic cell lines (Panc-1); this inhibition was 26 times more potent for the bufadienolide-containing fractions, as opposed to the alkaloid compounds; cinobufotalin, cinobufagin, and bufalin had very similar ability to inhibit the proliferation of Panc- 1 cells in comparison with resibufogenin, with $\mathrm{IC}_{50}$ values of 11.3 (cinobufotalin), 33.4 (cinobufagin), 8.1 (bufalin), and around 700 (resibufogenin) $\mathrm{ng} \mathrm{ml}^{-1}$, respectively (unpublished data).

We previously conducted a phase I dose-escalation study of huachansu in patients with solid malignancies; anticancer activity based on radiographical response was observed at the $20 \mathrm{ml} \mathrm{m}^{-2}$ dose cohort (Meng et al, 2009). Tolerance was excellent and toxicity from huachansu was not observed in this study. A previously reported study demonstrated radiographical response rates (RRs) of $10 \%$ and $16 \%$ in patients with hepatocellular and non-small-cell lung cancer (NSCLC; Yu and Ling, 2001). Huachansu was safely combined with chemotherapy (5-flurouracil, doxorubicin, and cisplatin) in patients with NSCLC, but without an observed increase in the RR; the huachansu-treated group was reported to have an improved quality-of-life (QOL) outcome (Shao, 2001).

Although huachansu is a widely used natural product (predominantly as monotherapy in China as standard-of-care for pancreatic and hepatobiliary malignancies), with a clearly defined mechanism of action, and prior preclinical and clinical studies indicating cancer efficacy, so far no well-designed randomised study has evaluated the potential benefit of huachansu when combined with conventional cytotoxic chemotherapy. Owing to the use of the intravenous extract of huachansu, as a standard-ofcare in China for the treatment of patients with advanced pancreatic cancer, and in vitro data supportive of its potential efficacy in pancreatic cancer cell lines, we undertook a randomised, single-blinded, phase II study gemcitabine plus either huachansu or placebo in this patient population, given that gemcitabine is a standard-of-care palliative systemic therapy in Western countries. The dose chosen was the most clinically active dose level observed in a phase I monotherapy study (Meng et al, 2009).

\section{PATIENTS AND METHODS}

\section{Patient selection}

Patients with surgically unresectable pancreatic adenocarcinoma were considered eligible for enrolment in the trial, which was conducted at the Department of Integrative Oncology, Fudan University Shanghai Cancer Centre, Shanghai, China. Inclusion criteria included age 18 years of age or older; histological (or cytological) diagnosis of unresectable (locally advanced and/or metastatic) pancreatic adenocarcinoma with measurable disease by Response Evaluation Criteria in Solid Tumours (Therasse et al, 2000); life expectancy of at least 3 months; Karnofsky performance status of greater than $60 \%$; and adequate organ function. There was no stratification utilised at the time of randomisation. The study was approved by the Institutional Review Boards of Fudan University Shanghai Cancer Center and MD Anderson Cancer Center, and followed the ethical principles of Good Clinical Practice in accordance with the Declaration of Helsinki. Subjects gave written and verbal consent before study entry. The clinical trial was registered with clinicaltrials.gov (identifier NCT00837239).

\section{Study design and treatment}

We conducted a randomised, phase II, single-center, singleblinded study of gemcitabine administered in combination with huachansu or gemcitabine with placebo. Patients were treated with weekly gemcitabine $1000 \mathrm{mg} \mathrm{m}^{-2}$ intravenously over $30 \mathrm{~min}$ on days 1,8 , and 15 every 28 days; this was combined with huachansu infusion intravenously $20 \mathrm{ml} \mathrm{m}^{-2}$ over 2 -h intravenous infusion 5 days a week for 3 weeks then 1 week off. While in the controlled group, saline as placebo was administrated with the same schedule of huachansu. Owing to the fact that TCM physicians and nurses traditionally have drawn up and administered TCM therapy, the study was single-blinded (i.e., the investigators were aware of the randomisation arm the patient was assigned to); research pharmacists were not available in the TCM unit where the study was conducted. In both arms, treatment continued unless there was evidence of progressive disease, unacceptable adverse event(s) after dose modification or delay, or patient decided to withdraw from the study. Subjects received therapy as an in-patient in the TCM unit at the Fudan University Shanghai Cancer Center. The phase II dose was derived from the radiographical activity observed in the phase I clinical trial. Anhui Jinchan Biochemistry Sharers Co. (a subsidiary of China Resource Sanjiu Medical Pharmaceutical Co., Ltd) provided the drug for this clinical trial from a single lot. Product quality control was assured by acquiring toad skins from designated source provinces (Anhui and Shandong, China) in China, establishing fingerprinting for the toad skin raw material, the semifinal extracts, and final product of huachansu. In addition, to eliminate the variation in the extracts of the toad skins collected from different geographical regions, each final product lot is a mix, at a fixed ratio, of toad skin extracts prepared from each source province. Finally, analytical methods have been established to monitor the quality of extract and product. As a regular quality control measure, the concentrations of certain compounds in the extract are measured, and high performance liquid chromatography fingerprinting is compared in the semifinal and final products.

\section{Assessment of toxicity and response}

Toxicity was graded by using the Common Terminology Criteria for Adverse Events version 3.0 (CTCAE v 3.0; Department of Health and Human Services, National Institutes of Health, National Cancer Institute, 2011). Dose adjustments were made depending on the toxicity observed with each treatment cycle. The gemcitabine dose was reduced to $75 \%$ of the starting dose based on grade 3 or 4 neutropenia, grade 2, 3, or 4 thrombocytopenia, or grade 3 or 4 non-haematological toxicities, respectively. Whereas the huachansu dose was modified only for cardiac toxicities to $50 \%$ of the starting dose based on grade 2 or 3 cardiac toxicity. Grade 4 cardiac toxicity would directly lead to discontinue treatment with huachansu. Treatment was delayed until recovery from any above event. If toxicity did not resolve within 4 weeks, patient would be removed from protocol treatment. Two dose reductions were 
allowed for each drug. If a third reduction was required, continued treatment was at the discretion of the investigator, that is, only if it was considered to be in the best interest of the patient.

Within 14 days before treatment, patients were required to undergo a complete history and physical examination including date and stage of pancreatic cancer and of metastases, prior cancer therapy, site(s) of metastases, performance status, and review of symptoms. Patients also complete blood count, urinalysis, renal and hepatic function tests, electrocardiogram, serum $\beta$-HCG for premenopausal women, electrolytes, and tumour markers of CA19-9. Tumour assessments via chest roentgenogram, computed tomography, or magnetic resonance imaging were required within 1 month before the start of treatment, and all other tests were done no more than 2 weeks before the start of therapy. During the course of treatment, history and physical examination, hepatic and renal function tests, electrolytes, CA19-9, toxicity assessment, and concomitant medications were collected, at the end of each cycle. Weekly assessments of complete blood count, platelet count, and differential were done. Assessment of response, including radiographical assessment, was performed approximately every 8 weeks; these were performed by a single blinded radiologist (CSN). Evaluation of QOL was performed using the MD Anderson Symptom Inventory (MDASI; Cleeland et al, 2000; Wang et al, 2004) and Functional Assessment of Cancer Therapy (FACT; Cella et al, 1993; Yu et al, 2000) pretreatment and then after every 8 weeks thereafter while on study. A TCM diagnosis was made at the study entry as part of the clinical trial but was not used to determine treatment randomisation.

\section{Statistical plan}

The primary objective of this study was to compare the 4-month PFS of patients treated with gemcitabine plus huachansu compared with gemcitabine plus placebo using pair-wise comparisons. Secondary end points were the comparison of time to progression (TTP), toxicity, RR, and QOL across the two treatment arms. In order to examine the primary aim comparing standard treatment versus standard treatment plus huachansu, we examined overall response defined as PFS at 4 months. Patients were randomised using a Bayesian algorithm. Initially, 20 patients were randomised equally to each treatment arm; thereafter, as response information accumulated, successive patients were randomised in favour of the treatment that, on average, elicits a higher response rate. The

Table I Operating characteristics for adaptive randomisation algorithm

\begin{tabular}{lcc}
\hline Operating & $\begin{array}{c}\text { Standard } \\
\text { treatment } \\
\text { alone }\end{array}$ & $\begin{array}{c}\text { Standard } \\
\text { treatment } \\
\text { huachansu }\end{array}$ \\
\hline True overall response rate & $50 \%$ & $50 \%$ \\
Average number of patients & 32.8 & 32.8 \\
Probability of selection as best & 0.519 & 0.481 \\
Probability of early selection & 0.039 & 0.034 \\
True overall response rate & $50 \%$ & $60 \%$ \\
Average number of patients & 28.8 & 36.2 \\
Probability of selection as best & 0.060 & 0.940 \\
Probability of early selection & 0.007 & 0.100 \\
True overall response rate & & $70 \%$ \\
Average number of patients & $50 \%$ & 35.6 \\
Probability of selection as best & 24.3 & 0.994 \\
Probability of early selection & 0.006 & 0.305 \\
True overall response rate & 0.002 & $80 \%$ \\
Average number of patients & & 30.7 \\
Probability of selection as best & $50 \%$ & 0.999 \\
Probability of early selection & 20.5 & 0.594 \\
\hline & 0.001 & \\
\hline & 0.001 & \\
\hline
\end{tabular}

randomisation probability for the experimental arm was the posterior probability that it had the highest probability of eliciting an overall response (i.e., $\rho \mathrm{GH}=\operatorname{Pr}[\mathrm{ORG}<\mathrm{ORGH} \mid$ data $]$ ), and the randomisation probability for $\mathrm{G}$ was $1-\rho \mathrm{GH}$. If at any point during the trial $\rho \mathrm{GH}>0.99$ (or $<0.01$ ) the trial would be terminated and GH would be selected as superior (inferior) (see Table 1). A maximum of 80 patients were estimated to be accrued on this study. The primary analysis was based on the intent-to-treat principle; all eligible patients were evaluated as randomised. Pair-wise correlations among variables were assessed using the Pearson correlation, or its non-parametric analogue, the Spearman correlation. Comparisons of continuous outcomes by treatment group were made using the $t$-test or the Wilcoxon rank sum test, as appropriate. Treatment comparisons of categorical variables were made using the $\chi^{2}$ or Fisher's exact test as appropriate (Fisher, 1950). Methods appropriate for longitudinal data analysis were used to analyse QOL data (FACT-G and MDASI). Time to progression and overall survival (OS) curves were obtained using the Kaplan-Meier method (Cox, 1972). Time to progression was measured from the date of study entry to the date of first progression, or censored at the date of last follow-up with stable disease. Overall survival was defined as the date of study entry to death, or censored at last known date of survival. Cox regression models of OS and TTP were utilised to identify simultaneous significant prognostic factors (Kaplan and Meier, 1958). Statistical analysis was performed using the SPSS program (SPSS, Chicago, IL, USA).

\section{RESULTS}

\section{Baseline patient characteristics}

This study accrued 80 patients between February 2008 and February 2010. Three patients with pancreatic cancer were initially treated with gemcitabine plus huachasu to observe for safety of the combination. One patient was enrolled but did not receive study medication and was deemed unevaluable; 76 evaluable subjects were enrolled and randomised; given the similar outcomes in each treatment arm, 39 subjects were enrolled on the experimental arm and 37 subjects to the control arm. (i.e., there was not preferential assignment to one arm owing to a lack of a superior 4-month PFS observed for one arm). Patient demographics are represented in Table 2.

\section{Treatment duration and toxicity}

A summary of treatment administered by study arm is shown in Figure 1. A median of two cycles of treatment was given in both arms. There were no significant differences in the number of treatment cycles received among the two treatment arms $(P=0.412)$. The reasons for treatment discontinuation were disease progression, unacceptable toxicity, and patient withdrawal of consent (Table 3). The distribution of reasons for study withdrawal did not vary significantly among the two arms $(P=0.565)$. The grade 3 and 4 toxicities are shown in Table 4 .

\section{Objective RR}

A total of $66(86.8 \%)$ patients had measurable lesions and were evaluable for response (34 patients in arm A and 32 patients in arm B). No complete response was observed in either treatment group. The partial response as assessed by the investigators was three patients $(8.8 \%)$ with gemcitabine plus huachansu and one patient (3.1\%) with gemcitabine plus placebo. There were no significant differences in the objective RR among the two arms $(P=0.332)$. When considering all the patients randomly assigned in the trial (intent-to-treat population), the RR was $7.7 \%$ ( 3 of 39 patients) in the experimental arm and $2.7 \%$ ( 1 of 37 patients) in the control arm. 
Table 2 Baseline characteristics of patients treated with gemcitabine and huachansu or gemcitabine and placebo

\begin{tabular}{|c|c|c|c|c|c|c|c|}
\hline \multirow[b]{3}{*}{ Characteristic } & \multicolumn{4}{|c|}{ Treatment arm } & & & \\
\hline & \multicolumn{2}{|c|}{$\begin{array}{l}\text { Gemcitabine } \\
+ \text { huachansu }\end{array}$} & \multicolumn{2}{|c|}{$\begin{array}{c}\text { Gemcitabine } \\
+ \text { placebo }\end{array}$} & \multicolumn{2}{|c|}{ Total } & \\
\hline & $\begin{array}{l}\text { No. of } \\
\text { patients }\end{array}$ & $\%$ & $\begin{array}{c}\text { No. of } \\
\text { patients }\end{array}$ & $\%$ & $\begin{array}{l}\text { No. of } \\
\text { patients }\end{array}$ & $\%$ & $P^{\mathbf{a}}$ \\
\hline \multicolumn{8}{|l|}{ Gender } \\
\hline Male & 23 & 58.97 & 23 & 62.16 & 46 & 60.53 & 0.776 \\
\hline Female & 16 & 41.03 & 14 & 37.84 & 30 & 39.47 & \\
\hline \multicolumn{8}{|l|}{ Stage } \\
\hline Metastatic & 29 & 74.36 & 29 & 78.38 & 58 & 76.32 & 0.680 \\
\hline $\begin{array}{l}\text { Locally } \\
\text { advanced }\end{array}$ & 10 & 25.64 & 8 & 21.62 & 18 & 23.68 & \\
\hline \multicolumn{8}{|c|}{ Location of the tumour in the pancreas } \\
\hline Head & 17 & 43.59 & 14 & 37.84 & 31 & 40.79 & 0.803 \\
\hline Body & 9 & 23.08 & 8 & 21.62 & 17 & 22.37 & \\
\hline Tail & 13 & 33.33 & 15 & 40.54 & 28 & 36.84 & \\
\hline \multicolumn{8}{|l|}{ Prior surgery } \\
\hline Yes & 4 & 10.26 & 5 & |3.5| & 9 & 11.84 & $0.733^{b}$ \\
\hline No & 35 & 89.74 & 32 & 86.49 & 70 & 92.11 & \\
\hline \multicolumn{8}{|l|}{ Prior chemotherapy } \\
\hline Yes & 4 & 10.26 & 0 & 0.00 & 4 & 5.26 & $0.116^{b}$ \\
\hline No & 35 & 89.74 & 37 & 100.00 & 75 & 98.68 & \\
\hline Age (years) & \multicolumn{2}{|c|}{$60.2 \pm 9.5$} & \multicolumn{2}{|c|}{$61.7 \pm 9.9$} & \multicolumn{2}{|c|}{$60.9 \pm 9.6$} & $0.525^{c}$ \\
\hline $\begin{array}{l}\text { Karnofsky } \\
\text { performance } \\
\text { status }\end{array}$ & \multicolumn{2}{|c|}{$84.9 \pm 6.5$} & \multicolumn{2}{|c|}{$85.4 \pm 5.1$} & \multicolumn{2}{|c|}{$85.1 \pm 5.8$} & $0.690^{d}$ \\
\hline
\end{tabular}

${ }^{a} \chi^{2}$. bFisher's test. 'Student's $t$-test. ${ }^{d}$ Mann-Whitney test.

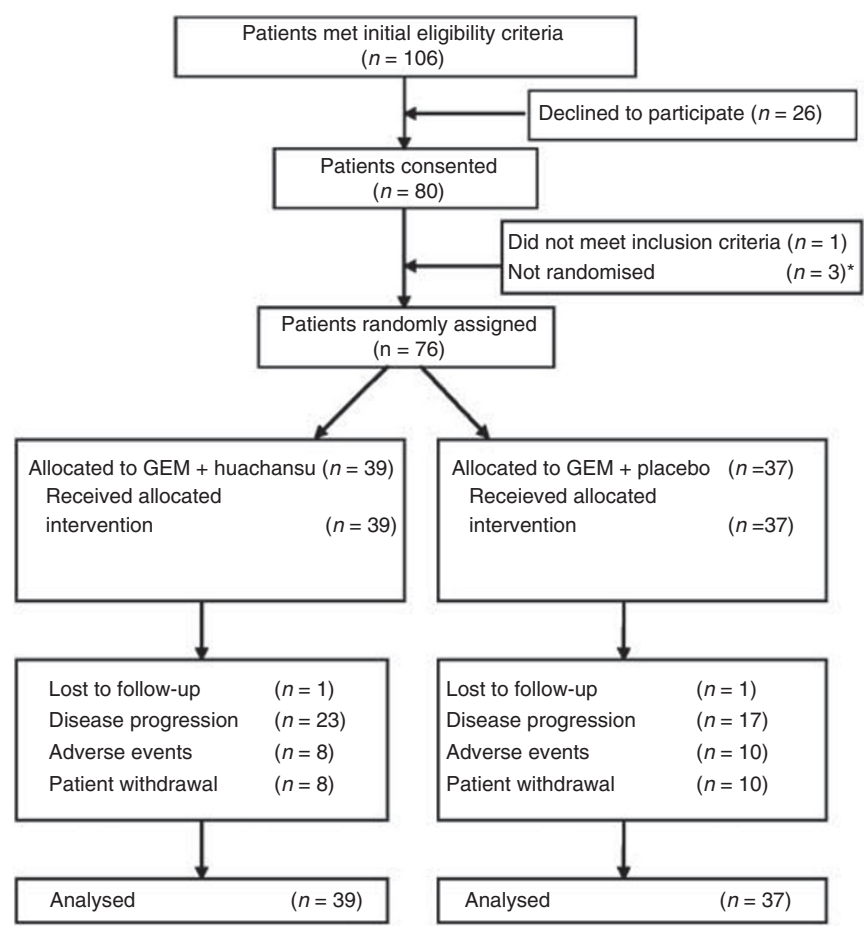

Figure I Consort diagram. * Three patients with pancreatic cancer were initially treated with gemcitabine plus huachansu to observe for safety of the combination.
Table 3 Number of doses of treatment received and reason for treatment discontinuation

\begin{tabular}{|c|c|c|c|c|}
\hline \multirow[b]{3}{*}{ Parameter } & \multicolumn{4}{|c|}{ Treatment arm } \\
\hline & \multicolumn{2}{|c|}{$\begin{array}{l}\text { Huachansu }+ \\
\text { gemcitabine } \\
(n=39)\end{array}$} & \multicolumn{2}{|c|}{$\begin{array}{l}\text { Placebo }+ \\
\text { gemcitabine } \\
\quad(n=37)\end{array}$} \\
\hline & No. & $\%$ & No. & $\%$ \\
\hline Mean no. of total cycles & 2.7 & & 2.4 & \\
\hline s.d. & 2.0 & & 2.0 & \\
\hline Median & 2 & & 2 & \\
\hline Range & $0-10$ & & $0-9$ & \\
\hline \multicolumn{5}{|l|}{ Off-treatment reason } \\
\hline Disease progression/symptom deterioration & 23 & 59 & 17 & 46 \\
\hline Toxicity/adverse effects/complications & 8 & 21 & 10 & 27 \\
\hline Patient withdrawal & 8 & 21 & 10 & 27 \\
\hline
\end{tabular}

Table 4 Grade 3 and 4 haematological and non-hematological toxicities (treatment-related)

\begin{tabular}{|c|c|c|c|c|}
\hline \multirow[b]{3}{*}{ Toxicity } & \multicolumn{4}{|c|}{ Treatment arm } \\
\hline & \multicolumn{2}{|c|}{$\begin{array}{c}\text { Gemcitabine }+ \\
\text { huachansu }(n=39)\end{array}$} & \multicolumn{2}{|c|}{$\begin{array}{l}\text { Gemcitabine }+ \\
\text { placebo }(n=37)\end{array}$} \\
\hline & Number & $\%$ & Number & $\%$ \\
\hline \multicolumn{5}{|l|}{ Haematological } \\
\hline Neutropenia & 8 & 21 & 7 & 19 \\
\hline Thrombocytopenia & 2 & 5 & 4 & 11 \\
\hline Anaemia & 5 & 13 & 2 & 5.5 \\
\hline \multicolumn{5}{|l|}{ Non-haematological } \\
\hline Bilirubin & 0 & & & \\
\hline AST & 0 & & & \\
\hline $\mathrm{ALT}$ & 0 & & & \\
\hline Nausea & 2 & 5 & & \\
\hline Vomiting & 0 & & 2 & 5.5 \\
\hline Skin & I & 2.5 & & \\
\hline
\end{tabular}

\section{Overall survival and TTP}

The median TTP in the eligible and treated patients was 98 days (95\% CI, 89.0-158.0 days) with gemcitabine plus huachansu and 115 days (95\% CI, 90.2-156.1 days) with gemcitabine plus placebo. There were no significant differences in the TTP among the two arms $(P=0.825)$. The median OS was 160 days ( $95 \% \mathrm{CI}, 151.0-225.4$ days) in the experimental arm and 156 days (95\% CI, 174.1-269.3 days) in the control arm. Stratified log-rank $P$-value was 0.339 . In the same population, 6-month OS rates were $30.5 \%$ and $41.7 \%$, respectively $(P=0.984)$. The median 4 -month progression free survival was 99 and 98 days, respectively $(P=0.679)$. The comparison did not demonstrate a statistically significant difference; Kaplan-Meier survival curves are demonstrated in Figure 2.

To assess the influence of prognostic factors, the relationships between the survival outcomes and the following variables were investigated in COX models: sex, age, tumour location (head/body or tail), tumour stage (locally advanced/metastasis), prior surgery, prior chemotherapy, performance status, and treatment group. We performed multivariate analysis of these factors for TTP and OS times. Among these factors, only the performance status (hazard ratio: 0.923 ; $95 \%$ CI: $0.869-0.980 ; P=0.009$ ) and stage (hazard ratio: $0.458 ; 95 \%$ CI: $0.232-0.907 ; P=0.025)$ showed a significant 
Overall survial (days)

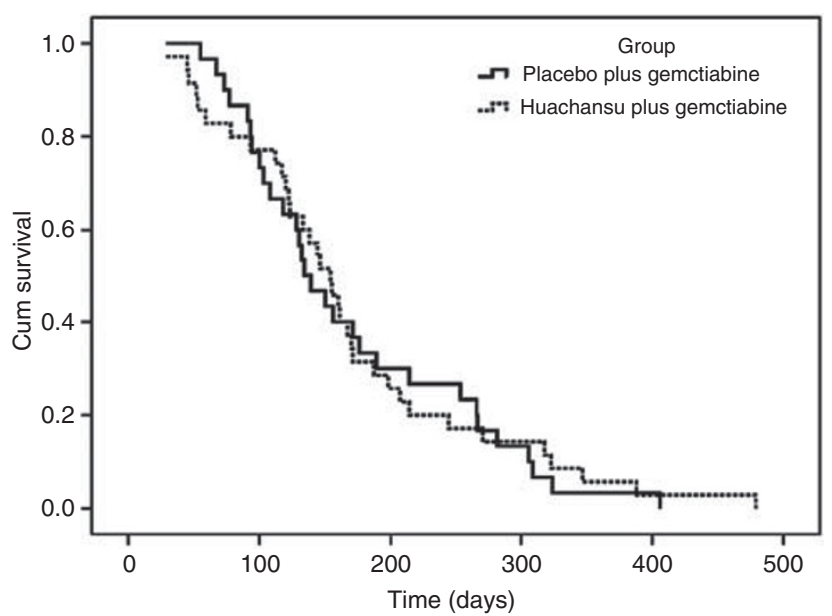

Progression-free survival (days)

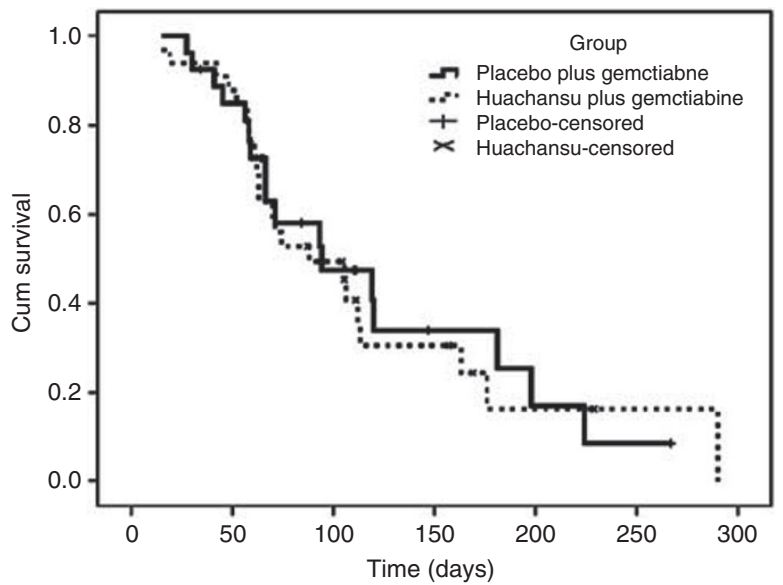

Figure 2 Kaplan-Meier curves for OS and PFS.

value for OS time, and no factors exerted a significant influence on TTP.

\section{Symptom severity}

There were 76 MDASI questionnaires completed at baseline. At baseline, pain, loss of appetite, dry mouth, distress, and fatigue were the most prominent symptoms noted by the patients. Some level of pain was present at baseline in $77.5 \%$ of patients. There were no symptom or QOL differences between the two arms at baseline. There were no group differences in the MDASI Symptom Severity or Interference scores or the FACT scores in any treatment cycle or at the end of treatment (See Supplementary Table 1). Traditional Chinese medicine diagnosis at the time of study entry was not found to be associated with treatment toxicity, treatment outcome, or OS. Biochemical response rate (serum CA19-9 decline) was not statistically different between the two treatment arms (data not shown).

\section{DISCUSSION}

This study is the first randomised clinical trial evaluating huachansu when combined with cytotoxic chemotherapy. In this study, there was not a clinical benefit observed with the addition of huachansu to gemcitabine in the treatment of patients with advanced pancreatic cancer. In this regard, the outcome is similar to over 30 previously published well-designed randomised clinical trials in patients with advanced pancreatic cancer evaluating gemcitabine combined with other cytoxic agent or biologic agent (Di Marco et al, 2010), all of which have been negative, with the exception of modest additional benefit observed with gemcitabine plus capecitabine (Cunningham et al, 2009) and gemcitabine plus erlotinib (Moore et al, 2007) when compared with placebo. The lack of efficacy seen in this single trial does not preclude possible efficacy in other solid malignancies, and deserves further evaluation.

The lack of toxicity observed in this study might indicate that too low a dose of huachansu was chosen for combination with gemcitabine. The dose chosen was that dose that was associated with observed clinical efficacy in the phase I trial; further doseescalation studies may be required to determine the optimal dose of this form of TCM. A major logistical problem with the intravenous formulation of this agent is the relatively short half-life, and the need for frequent parenteral infusions of the agent. A major limitation of this study is the lack of knowledge regarding the optimal dosing of huachansu, either as monotherapy or in combination with cytotoxic chemotherapy, as well as the incomplete data on gemcitabine pharmacokinetics when combined with huachansu. However, we tested a dose and treatment schedule that is the standard-of-care in China for huachansu. A significantly more potent oral formulation of this agent is under development, which will help in the ease of administration of the agent obviating the need for daily infusions; phase I dose-escalation studies of this formulation may detect toxicity, potentially cardiotoxicity, with some assurance that the relevant targets are being affected with its administration. This formulation deserves evaluation in patients with solid malignancies, even potentially patients with pancreatic cancer; however, it is not clear whether it is necessary to combine such a second-generation huachansu product with gemcitabine, as suggested by the National Cancer Institute consensus report on pancreatic cancer treatment ( $\mathrm{Yu}$ and Ling, 2001). Indeed, previously reported phase II trials, demonstrating efficacy of huachansu in solid malignancies, mainly utilised the agent as monotherapy (Yang and Zhang, 1987; Philip et al, 2009). Development of a more potent oral formulation will require careful evaluation to assess the optimal dose as well as identifying putative biomarkers of treatment efficacy.

This clinical trial highlighted significant technical, legal, and logistical barriers to performing transnational studies, many of which were overcome successfully. Future studies would likely benefit from patient accrual at both Eastern and Western sites concurrently, which would facilitate the performing of correlative studies critical to drug development. Despite major impediments to the rigorous clinical evaluation of TCM, the knowledge gained from the better understanding of the efficacy (or lack thereof), and which patient populations are most likely to benefit from these drugs, would be of great benefit to patients, from both medical cultures.

Although TCM is particularly focused on alleviation of symptoms and improvement in overall health and well-being, in this trial we could not demonstrate a benefit in QOL in those patients treated with huachansu. It may require longer exposure of treatment before clinically significant changes in patient well-being can be observed; owing to the natural history of advanced pancreatic cancer, as well as the design of the clinical trial, the time of exposure to huachansu was relatively short. In addition, huachansu is typically not used as monotherapy separate from other TCM herbals, and future trials could examine the combination of huachansu with other TCM products.

The results of this randomised clinical trial do not support the use of huachansu in combination with gemcitabine in the treatment of advanced pancreatic cancer. Traditional Chinese medicine therapies should continue to be evaluated in clinical trials to determine if these forms of therapy derive benefit to the patient. Lack of efficacy in patients with pancreatic cancer does not preclude evaluation in other solid malignancies, particularly those 
for which preclinical data suggest potential efficacy. In addition, phase I studies of newer, and potentially more potent, oral formulation of huachansu are planned, and warrant evaluation in patients with advanced solid malignancies. The demonstrated in vitro anticancer properties of huachansu (wild toad extract) justify continued evaluation of these agents in clinical trials.

\section{ACKNOWLEDGEMENTS}

This work was supported by National Institute of Health grant U19CA121503-01. The study drug huachansu was

\section{REFERENCES}

Boik J (2001) Using natural compounds in combination. In Natural Compounds in Cancer Therapy, Farnell S (ed), pp 4-5. Oregon Medical Press: Princeton, MN

Cancer Therapy Evaluation Program: Common Terminology Criteria for Adverse Events. version 3.0. Department of Health and Human Services, National Institutes of Health: National Cancer Institute. Available from: URL: http://www.eortc.be/services/doc/ctc/ctcaev3.pdf (accessed 20 December 2011)

Cella DF, Tulsky DS, Gray G, Sarafian B, Linn E, Bonomi A, Silberman M, Yellen SB, Winicour P, Brannon J, Eckberg K, Lloyd S, Purl S, Blendowski S, Goodman M, Barnicle M, Stewart I, McHale M, Bonomi P, Kaplan E, Taylor S, Thomas CR, Harris J (1993) The Functional Assessment of Cancer Therapy scale: development and validation of the general measure. J Clin Oncol 11: 570-579

Cleeland CS, Mendoza TR, Wang XS, Chou C, Harle MT, Morrissey M, Engstrom MC (2000) Assessing symptom distress in cancer: The M. D. Anderson Symptom Inventory. Cancer 89(7): 1634-1646

Cox DR (1972) Regression models and life tables. J R Stat Soc B 34: 187-220

Cragg GM, Schepartz SA, Suffness M (1993) The taxol supply crisis: new NCI policies for handling the large scale production of novel natural product anticancer and anti-HIV agents. J Natl Cancer Prod 56: 1657-1668

Cragg GM, Newman DJ, Sander KM (1997) Natural products in drug discovery and development. J Natl Cancer Prod 60: 52-60

Cunningham D, Chau I, Stocken DD, Valle JW, Smith D, Steward W, Harper PG, Dunn J, Tudur-Smith C, West J, Falk S, Crellin A, Adab F, Thompson J, Leonard P, Ostrowski J, Eatock M, Scheithauer W, Herrmann R, Neoptolemos JP (2009) Phase III randomized comparison of gemcitabine versus gemcitabine plus capecitabine in patients with advanced pancreatic cancer. J Clin Oncol 27: 5513-5518

Cuo XD, Cuei YA, Wang JH, Qin S, Chen HY (2003a) The effect of cinobufacini on human gastric neoplasm cell line MGC-80-3. Chinese Clin Oncol 8: 33-37

Cuo XD, Cuei YA, Qin S, Chen HY, Wang JH (2003b) Effect of cinobufacini on tumor cell cycle and expression of bcl-2 protein. Mod J Intergrated Tradit Chin West Med 12: 567-568

Di Marco M, Di Cicilia R, Macchini M, Nobili E, Vecchiarelli S, Brandi G, Biasco G (2010) Metastatic pancreatic cancer: is gemcitabine still the best standard treatment? Oncol Rep 23: 1183-1192

Fisher RA (1950) Statistical Methods for Research Workers (11th edn), pp 107. Hafner Publishing Company: New York, NY

Guan J, Zhao XH, Jiang BS, Chen ZW, Qin QY (1993) Preliminary study on the antitumor mechanism of cinobufacini injection. J Penfu Med College 18: $78-81$

Kaplan EL, Meier P (1958) Nonparametric estimation from incomplete observations. Am Stat Assoc 53: 457-481

Liu BR, Xu XL, Liu WC, Meng XZ (2002) Effects of four extracts of traditional Chinese medicinal materials on the proliferation of human lung cancer A549 cell line. Chinese Pharmacol Bull 18: 94-96

Meng Z, Yang P, Shen Y, Bei W, Zhang Y, Ge Y, Newman RA, Cohen L, Liu L, Thornton B, Chang DZ, Liao Z, Kurzrock R (2009) Pilot study of provided by Anhui Jinchan Biochemistry Sharers Co., a subsidiary of China Resource Sanjiu Medical Pharmaceutical Co., Ltd.

\section{Conflict of interest}

PY and LC have received compensation from Anhui Jinchan Biochemistry Sharers Co. for consulting work.

Supplementary Information accompanies the paper on British Journal of Cancer website (http://www.nature.com/bjc) huachansu in patients with hepatocellular carcinoma, nonsmall-cell lung cancer, or pancreatic cancer. Cancer 115(22): 5309-5318

Moore MJ, Goldstein D, Hamm J, Figer A, Hecht JR, Gallinger S, Au HJ, Murawa P, Walde D, Wolff RA, Campos D, Lim R, Ding K, Clark G, Voskoglou-Nomikos T, Ptasynski M, Parulekar W. National Cancer Institute of Canada Clinical Trials Group (2007) Erlotinib plus gemcitabine compared with gemcitabine alone in patients with advanced pancreatic cancer: a phase III trial of the National Cancer Institute of Canada Clinical Trials Group. J Clin Oncol 25: 1960-1966

Philip PA, Mooney M, Jaffe D, Eckhardt G, Moore M, Meropol N, Emens L, O'Reilly E, Korc M, Ellis L, Benedetti J, Rothenberg M, Willett C, Tempero M, Lowy A, Abbruzzese J, Simeone D, Hingorani S, Berlin J, Tepper J (2009) Consensus report of the national cancer institute clinical trials planning meeting on pancreas cancer treatment. J Clin Oncol 27: 5660-5669

Shao GR (2001) The clinical observation on huachansu treatment in late stage lung cancer. Tianjin J Trad Chinese Med 18: 46-47

$\mathrm{Su} \mathrm{YH}, \mathrm{Nu} \mathrm{X}$ (2001) Evaluation of pharmacodynamic effect of pharmaceutical agents of Chan Su. J Beijing Univ TCM 24: 51-54

Su YH, Huang XQ, Zhang DZ, Zhang YN, Xie JM, Linh CQ (2003) HPLC separation and determination of bufadienolide in cinobufacini injection. Chin Tradit Pat Med 25: 24-27

Sun GL, Wang ZY, Chen SY (1984) The preliminary study of Chansu on immune function. J Chinese Interg Med 4: 297-299

Therasse P, Arbuck S, Eisenhauer EA, Wanders J, Kaplan RS, Rubinstein L, Verweij J, Van Glabbeke M, van Oosterom AT, Christian MC, Gwyther SG (2000) New guidelines to evaluate the response to treatment in solid tumours. J Natl Cancer Inst 92: 205-216

Wang JZ, Yan JG, Zhang J, Liu JC (2000) Studies on the analgestic effect of cinobufacini injection and its mechanism. J Linyi Medical College 22: 81-84

Wang XS, Wang Y, Guo H, Mendoza TR, Hao XS, Cleeland CS (2004) Chinese version of the M. D. Anderson Symptom Inventory: validation and application of symptom measurement in cancer patients. Cancer 101: $1890-1891$

Wei X, Chen CZ, Wu T, Yang X, Liu G (2007) WITHDRAWN: Medicinal herbs for esophageal cancer. Cochrane Database Syst Rev 18(3): CD004520

Yang ZH, Zhang MY (1987) The effect of huachansu and its fraction Bf1, bF2 on immune function in mice. Shanghai J Immune 7: 96-98

Yu CL, Fielding R, Chan CL, Tse VK, Choi PH, Lau WH, Choy DT, O SK, Lee AW, Sham JS (2000) Measuring quality of life of Chinese cancer patients: a validation of the Chinese version of the Functional Assessment of Cancer Therapy-General (FACT-G) scale. Cancer 88: 1715-1727

Yu SH, Ling CQ (2001) Clinical effect of huachansu in treatment of liver cancer. Acad J Sec Mil Med Univ 22: 83-84

Zhang ZY, Zhang KH, Wang ZW, Zhu JQ, Zhu ZH, Huang DQ (1999) Cytotoxicity of HuaChanSu on three digestive tract tumour cells in vitro. Chinese Med Pharma Clin 15: 28-29

This work is published under the standard license to publish agreement. After 12 months the work will become freely available and the license terms will switch to a Creative Commons Attribution-NonCommercial-Share Alike 3.0 Unported License. 